\title{
Postpartum Hemorajinin Yönetiminde Kanıt Temelli Yaklaşımlar
}

\section{Evidence-Based Approachs in The Management of Postpartum Haemorrhage}

Özlem Güner,

Gül Ertem

Ege Üniversitesi Hemşirelik Fakültesi Kadın Sağlığı ve Hastalıkları Hemşireliği Anabilim Dalı

Geliş Tarihi/Received: 02 Şubat 2016 Kabul Tarihi/Accepted: 22 Ağustos 2017

\begin{abstract}
Özet
Ülkemizde maternal mortalitenin birinci sebebi olan postpartum hemoraji; dünyada anne ölümlerinin yaklaşık 1/4'ünden sorumlu olup, bebeğin doğumundan sonraki ilk 24 saat içinde vajinal olarak $500 \mathrm{ml}$ yada daha fazla kan kaybedilmesi olarak tanımlanırken, şiddetli postpartum hemoraji ise $1000 \mathrm{ml}$. den fazla kan kaybını ifade etmektedir. En sık rastlanan nedenleri; uterus atonisi, genital traktus yaralanmaları ve plasenta retansiyonudur. Tedavisinde uterin fundusa etkin masaj uygulanması, myometriumu kontrakte eden ajanların kullanımı, hipogastrik veya uterin arter ligasyonu yada embolizasyonu gibi birçok yöntem kullanılmaktadır. Buna rağmen ülkemizde maternal mortalitenin birinci sebebi postpartum hemorajidir. Postpartum hemorajiye bağlı yaşanan maternal mortalite oranlarını azaltmakta tedavi ve bakım da kanıt temelli yaklaşımlar önem kazanmaktadır. Postpartum hemorajinin önlenmesinde ve tedavisinde doğumun üçüncü evresine yönelik çeşitli uygulamalar, farmakolojik ve cerrahi yaklaşımlar kullanılmakla birlikte tüm tedavilerde yeterli düzeyde kanıta dayalı çalışmaların olmadığı görülmektedir. Postpartum hemorajinin tedavi edici yaklaşımlarının büyük bir kısmında klinik verilerin sınırlı olduğu görülmektedir. Bu nedenle, bu derlemede postpartum hemorajinin önlenmesinde ve tedavisinde yer alan güncel yaklaşımlar belirlemek ve uygulanan girişimlerin yeterlilik düzeyi konusunda sağlık profesyonellerinin bilgilendirilmesi amaçlanmaktadır.
\end{abstract}

Anahtar kelimeler: Postpartum, hemoraji, kanıta dayalı uygulamalar

\section{Abstract}

Postpartum haemorrhage (PPH) which is the first cause of maternal mortality in our country is responsible for about $25 \%$ of maternal deaths in the world. While PPH is defined as loss of $500 \mathrm{ml}$ or more of blood from the genital tract within 24 hours of thebirth of a baby, severe PPH is blood loss exceeding $1,000 \mathrm{~mL}$. The most common causes are uterine atony, genital tract injuries and placental retention. Many methods are used such as effective implementation of the uterine fundus massage, the use of agents which myometrium contact, hypogastric and/or uterine artery ligation or embolization in its treatment. Despite this, PPH is the primer cause of maternal death in our country. To reduce maternal mortality rates caused by dependence of $\mathrm{PPH}$, evidence-based approaches are important in treatment and care. Pharmacological, surgical approaches and various applications for the third stage of labour in the prevention and treatment of PPH are used. But there are no evidencebased studies at adequate levels for all treatment. The clinical data in a large part of the PPH/therapeutic approach are limited. Therefore, it is intended in this article to determine the current approaches related to the prevention of postpartum haemorrhage and to inform health professionals about the adequacy of the initiatives implemented.

Keywords: Postpartum, hemorrhage, evidence-based practices

\section{GíRiş}

Postpartum hemorajinin (PPH) evrensel olarak kabul edilen bir tanımı olmamakla birlikte, klasik tanımı bebeğin doğumundan sonraki ilk 24 saat içinde spontan vajinal yolla doğumda $500 \mathrm{ml}$, sezaryen sonrası 1000 ml'den fazla kan kaybedilmesi olarak adlandırılır. Postpartum hemorajinin başka bir tanımı ise, postpartum hematokrit düzeyinde \%10'dan daha fazla düşüş olması, hemodinamide bozukluğa yol açan ve anne hayatını tehdit eden, kan ve kan ürünlerinin replasmanını gerektirecek obstetrik hemorajilerdir. Postpartum hemoraji ilk 24 saatte ortaya çıkan primer (erken) ve postpartum 24. saatten 12. haftaya kadar devam eden daha kronik seyirli, mortalitesi daha düşük olan sekonder (geç) postpartum kanamalar olarak ikiye ayrılır (1).
$\mathrm{PPH}$, günümüzde gelişmekte olan ve gelişmiş ülkelerde maternal morbidite ve mortalitenin önemli sebeplerinden biridir. Tüm dünyada anne ölümleri nedenleriarasında kanama ilküçsıradayer almaktadır. Türkiye'de 2005 yılında yapılan Ulusal Anne Ölümleri Çalışması'nda (UAÖÇ), anne ölümlerinde birinci sırayı kanamaların (\%24.9 postpartum, intrapartum,antepartum) aldığı belirtilmektedir. Anne ölümlerinin \%15.7'si postpartum hemorajiden kaynaklanmakta olup bu ölümler de postpartum ölümlerin yüzde 50'sinden fazlasını oluşturmaktadır (2).

$\mathrm{Bu}$ derlemede anne kaybına yol açabilen postpartum hemoraji ile başedebilmede sağlık profesyonellerinin daha etkin bakım verebilmeleri için, kanıta dayalı girişimleri belirlemek ve bu konu

Yazışma Adresi: Gül Ertem, Ege Üniversitesi Hemşirelik Fakültesi, Kadın Sağıı̆ı ve Hastalıkları Hemşireliği Anabilim Dalı, İzmir. 
hakkında literatür doğrultusunda bilgi sağlamak amaçlanmıştır.

\section{ETYOLOJi VE RISK FAKTÖRLERI}

Talasemi ve demir eksikliği gibi anemi kökenli yada ileri dehidratasyon, preeklampsi gibi kan volümünde azalma oluşturan durumlarda oluşan akut PPH'lerde, maternal hemodinamik bozulma daha hızlı ve ağır bir tablo olarak meydana gelir.

PPH'ye neden olan faktörler $4 \mathrm{~T}$ terminolojisi ile sıralanabilir:

. Tonus: uterus atonisi, mesane distansiyonu

. Tissue: plasenta ve pıhtı retansiyonu

. Trauma: uterus, serviks yada vajina hasarı

- Thrombin: koagulopati (kazanılmış yada önceden mevcut olan)

Doğumun 3. devresinde, plasentanın ayrılmasının ardından meydana gelen uterusun myometriyum tabakasındaki kasılmaların oluşturduğu vasküler okluzyon, uterusun damarlarından kaviteye doğru kan akışının önlenmesini, 3. devredeki kanamanın minimalize olmasını sağlar. Doğumun 3. devresinde güçlü myometriyal kontraksiyonların oluşmadığı durumlarda uterus atonisi en sık ve önemli $\mathrm{PPH}$ sebeplerindendir (2).

\section{PPH YÖNETIMIMINDE KANITA DAYALI YAKLAŞIMLAR}

1-Doğumun Üçüncü Evresinin Yönetimi

Doğumun üçüncü evresi; fetusun doğumunu takiben başlamakta olup, plasenta ve fetal membranların çıkarılması ile sonlanmaktadır. Üçüncü dönemin zamanı ve bu döneme ait komplikasyonlar; plasenta ayrılma süresinin uzunluğu ve myometriyumun kontraksiyon gücünün bileşimine bağlı olduğu bildirilmektedir. Plasentanın \%90 oranında 10 dakikalık süre içinde ayrılması beklenir (genellikle 5 -18 dakika) ve ciddi kanama söz konusu değilse 30 dakika beklenebilir. Bu sürede anne açısından risk oluşturabilecek konular; postpartum hemoraji başta olmak üzere, plasenta artıklarının uterusta kalması ve uterus inversiyonudur. Doğumun üçüncü evresinde genel olarak, aktif ve fizyolojik bekle-gör yönetimi olmak üzere iki tür yaklaşım söz konusudur. Kanıt temelli yönetimlerde aktif yönetim daha fazla kullanılmaktadır. Aktif yönetim; bebeğin doğumundan sonraki iki dakika içinde uterin kasılmaları indüklemek için proflaktik oksitoksik ajan veya prostaglandin verilmesini, plesantal ayrılmayı artırmak için kordonun hızla kesilmesinin ardından klemplenmesini ve denetim altında kordonun çekilmesi ile plesantal doğumun yaptırılmasını içermektedir (1).

Rogers et al. (3), yapmış olduğu randomize kontrollü çalışma sonucunda doğumun üçüncü evresinin aktif olarak yönetilen her 1000 kadın 100'ünde doğum sonrası kanamanın önlenebilir olduğu, 20'sinde 1000 ml'den daha fazla kan kaybı olduğu saptanmıştır. Prendiville adaşlarının (2000) yaptığı beş çalışmanın incelendiği sistematik derlemede, doğumun üçüncü evresinin aktif yönetiminin bekle-gör yönetimine göre bu döneme özgü oluşabilecek komplikasyonlar ve kaybedilen kan miktarı yönünden daha iyi olduğu ve normal doğumda rutin uygulama olması gerektiği savunulmuştur (4). Yine benzer bir çalışmada, Begley et al. (5) yaptığı 8247 kadını içeren yedi çalışmanın sistematik derlemesinde, doğumun üçüncü evresinin aktif yönetimi ile fizyolojik bekle-gör yöntemi karşılaştırılmış ve aktif yönetim uygulanan kadınlarda kanama miktarının daha az olduğu saptanmıştır. Ancak bunun aktif yönetiminde uygulanan girişimlerden hangisinden kaynaklandığının ayrımın yapılması gerekliliği savunulmuştur. Her iki yöntemde önerilmekte olup, özellikle Dünya Sağlık Örgütü (DSÖ) geç klemplemenin uygulandığı aktif yönetimi önermektedir (6). Kanıtlar aktif doğum yönetimini, postpartum hemoraji, postpartum anemi ve kan transfüzyonu ihtiyacını, insidansını ve şiddetini azalttığını göstermektedir. Aktif yönetime yönelik yapılmış çalışmaların sonuçları doğrultusunda postpartum hemorajiyi önlemek için doğumun üçüncü evresinin aktif yönetimi önerilmektedir (I-A)

\section{A-Kordon Klempleme}

Göbek kordonunu klempleme zaman yönünden değişkenlik göstermektedir. Bu değişkenlik; doğumun 3. dönemin aktif yönetiminde, erken klempleme; kordonda nabız varlığı veya yokluğuna bakılmaksızın doğum sonu ilk 60 saniye içinde yapılmaktadır. Doğumun 3. dönemin bekle-gör yönetim şeklinde, geç klempleme için korddaki nabzın durması beklenir. Geç klempleme plesanta tranfüzyonuna yönelik kolaylık sağlamaktadır. Böylece kan hacminde $\%$ 30'luk bir artma sağlanarak hemoglobin ve hematokrit seviyelerinde de artma meydana gelir. Bu durumun akabinde demir deposunda artma oluşur ve bebeklik sürecinde anemik durumla karşılaşma oranında azalma yaşanır. Rh negatif annelerde, erken klempleme fetomaternal transfüzyon olasıllığını ve bu yolla izoimmünizasyon riskinde artma görülür. Erken klempleme prematüre bebeklerde solunum zorluğu sendromu olasıllığında artma oluşturduğu bildirilmektedir $(7,8)$. Mcdonald ve Middleton'un (9) yaptığı Cochrane'de yayınlanan meta-analizde, 
umblikal kordun erken (doğum sonu ilk 60 saniye içinde) ve geç (doğum sonu 60 saniyeden sonra) klemplenmesinin maternal ve neonatal sonuçlarını inceleyen 11 randomize kontrollü çalışma da; geç klempleme ile PPH insidansında fark bulunamamış; ancak fototerapi gerektiren neonatal sarılık ve yenidoğanlarda 6 . aya kadar yüksek ferritin ve hemoglobin seviyelerinin belirlenme insidansında artma olduğu bulunmuştur. Elimizde veriler sonucunda; kordonda erken yada geç klempleme uygulamasına yönelik öneri verilmesini sağlayacak yeterli kanıt olmadığından, bu konuda Cochrane yayın taramasına ihtiyaç duyulmaktadır $(E)$.

\section{B-Denetim Altında Kordonun Çekilmesi}

Kordonun denetim altında çekilmesi, bir elin alt abdomene yerleştirilmesi ve diğer el ile umblikal kordun yukarıya doğru karşıt basınçla sürekli şekilde çekilmesidir. Güçlü kontraksiyonları olan uterus durumunda pubik kemiğin yukarısından ters itme uygulamadan, kesinlikle kordon çekme işlemi uygulanması yapılmamalıdır. Denetim altında kordun çekilmesi ile ilişkili olarak, kordon yırtılması (\%3) ve uterus inversiyonu(yönetimin yanlış uygulanması nedeniyle) gibi az görülen ama ciddi komplikasyonlar gelişebilmektedir (10).

Prick et al. (11) yaptığı vajinal doğum yapan 626 kadını içeren randomize kontrollü çalışmada; kontrollü kord çekmenin uterotonik kullanımı azalttığı saptanmıştır. Sheldon et al. (12) yaptığı 4 ülkeden 8221 kadını içeren konrollü kord çekme, uteretonik ile kontrollü kord çekme veya uterus masajının karşılaştırıldığı deneysel bir çalışmada; post partum hemorajiyi önlemede ayrı ayrı masaj ve kontrollü kord çekme uygulamalarının uterotonikler kadar etkili olduğu saptanmıştır. Du et al. (13) yaptığı beş RKÇ ve 30532 kadını içeren meta analizde; doğumun üçüncü evresinde kontrollü kord çekme ile müdahalesiz grupların karşılaştırılmasında kontrollü kord çekme uygulanan grupta kan tranfüzyonu ve uterotoniklere duyulan ihtiyacın azaldığı saptanmıştır. Kadınlarda post partum kanamayı önlemek ve azaltmak için denetim altında kordonun çekilmesinin yararlı olabileceği saptanmıştır (I-A).

\section{C-Uterus Masajı}

Uterus masajı, uterus atonikse hem tek elle fundus üzerinden hem de çift elle vajinal anterior forniks ve abdomenden fundusun posterior açısından uygulanabilmektedir. Uterusmasajı gevşeyenuterusun tekrar kasılmasını sağladığı, lokal prostaglandin salımını uyardığı ve böylece doğum sonu kan kaybını azalttığı için önemlidir. Uterus göreceli olarak atonik olsa bile, çift elle masaj kanamada azalma sağlar, böylece kan kaybını etkilemede resusitasyon şansı verir (10).

Uluslararası Ebelik Konfederasyonu ve Uluslararası Jinekoloji ve Obstetrik Federasyonu (2004), kasıımalarda artış sağlamak için plasentanın doğumunu takiben rutin olarak uterus masajının yapılması gerekliliğinin üzerinde durmaktadır (14). Hofmeyr et al. (15) yaptığı iki randomize kontrollü çalışmayı içeren sistematik derlemede; plesanta doğumundan sonra rutin olarak uterotonik yapılan kadınlara uygulanan uterus masajı ile masaj uygulanmayan gruplar karşılaştırılmıştır. 200 kadını içeren ilk araştırmada, doğum sonu 60 dakika boyunca her 10 dakikada bir uterus masajının yapılmasının kan kaybını ve ilave uterotoniklerin kullanımına duyulan gereksinimi azalttığı bulunmuştur. Ayrıca, 500ml'den daha fazla kan kaybı olan kadınların sayısında \%50 oranında azalma olduğu bulunmuştur. Uterus masajı uygulanan annelerde kan transfüzyonuna gereksinim duyulmazken, kontrol grubunda bulunan iki anneye kan transfüzyonu yapılmasına gereksinim duyulmuştur. 1964 kadını içeren ikinci çalışmada ise uterus masajının yapılmasının kan kaybında bir azalma sağlamadığı bildirilmiştir. Ayrıca bu makale de; uterus masajının dezavantajları olarak annenin yapılan masajdan rahatsız olması ve personelin zamanının kullanılması olarak bildirilmiştir. İldan ve Kavlak'ın (16) yaptığı 60 kadını içeren deneysel bir çalışmada; vajinal doğumdan sonra, ilk 24 saatte uygulanan fundus masajın uterus involüsyonuna ve loşia rubra miktarına etkisini incelemiştir. Masaj grubuna, ilk bir saatte 15 dakika arayla 45 saniye; 12. saate kadar ise saat başı 45 saniye fundus masajı yapılmıştır. Masaj gurubu kadınların postpartum 24 saatteki toplam loşia miktarı kontrol grubunun toplam loşia miktarından daha az olduğu bulunmuştur. Postpartum hemorajiyi önlemek ve azaltmak için güvenli ve etkili bir tedavi olabileceğini saptamış ancak çalışmalardaki sınırlılıklar nedeniyle mutlaka başka çalışmaların yapılması gerekti saptanmıştır (IIB).

\section{2-TEDAVi}

A-Farmakolojik Yaklaşım (Uterotonik Ajanların Uygulanması)

Prostaglandin, oksitosin ve ergometrin uterusun kontraksiyonu sağlayan uterotonik ilaçlar olarak PPH'nin medikal tedavisinde kullanılmaktadır.dır.

a-Oksitosin: Oksitosin (Syntocinon); hipofizin arka lobundan salınan, doğum sırasında ve bebeğin 
meme emmesi ile dolaşıma karışan doğal oksitosin hormonuyla aynı işlevselliğe sahiptir. Oksitosin uterusun myometriyum tabakasındaki oksitosin reseptörlerinin sayısını artırarak gebeliğin son dönemlerinde, doğumda ve postpartum dönemde kasılmaları sağlar (17).

Syntocinon intravenöz olarak düşük dozda verilmesi; suni sancı denilen uterusta süre, kuvvet ve sıklık yönünden doğumda meydana gelen kontraksiyonlara benzer ritmik kasılmalara neden olur. Yüksek doz olarak infüzeedilmesi uterusun kontraksiyonlarında kalıcı etkiye neden olabilir. Damar içine hızlı olarak bolüs yapıldığı durumlarda taşikardi, ateş basması, hipotansiyonunda olduğu kısa süreli kas gevşemesi görülmüştür (18).

Cotter et al. (19) yaptığı 14 RKÇ içeren bir sistematik derlemede; doğum eyleminin ardından oksitosinin kullanılması sonucunda kan kaybı miktarında azalma olduğu, ancak her doğum eyleminden sonra oksitosinin kullanımı durumunda oluşabilecek yan etkiler konusunda daha fazla araştırmaya greksinim olduğu vurgulanmıştır(19). Westhoff et al. (20) yaptığı, Cochrane collarabationda yer alan ve 10,806 kadını kapsayan 20 randomize kontrollü çalışmayı inceleyen meta analizde, 10 çalışmada profilaktik oksitosin ile plesabo; beş çalışmada oksitosin ile ergot alkoloidleri; diğer beş çalışmada da oksitosin+ergometrin ile ergot alkoloidleri postpartum hemorajiyi önleme açısından karşılaştırılmıştır. Profilaktik oksitosin ile plesabonun karşılaştırılmasında plesabo uygulanan kadınlarda terapötik uterotonik ihtiyacının arttığı saptanmıştır. Oksitosin ile ergot alkoloidlerinin karşılaştırılmasında tedavi etkinliği açısından oksitosinin kanamaları önleme ve azaltmada daha etkili olduğu, aynı zamanda ergot alkoloidlerinin kullanıldığı vakalarda bulantı ve kusma gibi yan etkilerin olduğu görülmüştür. Oksitosin+ergometrin ile ergot alkoloidlerinin karşılaştırılmasında kanamayı önleme ve azaltma açısından fark saptanmamıştır. Eldeki veriler, postparum hemoraji tedavisinde oksitosin kullanımının postpartum kanamayı önlemede ve azaltmada etkin bir tedavi olduğunu göstermekte olup ancak yan etkisinin belirlenmesi için çalışmalara intiyaç duyulduğunu ortaya koymaktadır (I-A).

Oksitosin agonistleri: PPH'yi önlemede en etkin olduğu düşünülen karbetosin; doğal oksitosin ile benzer farmakolojik ve klinik niteliklere, agonist özelliklere, uzun etki süresine sahip yapay bir ajandır. $\mathrm{Bu}$ ajan uterusun myometriyum tabakasındaki oksitosin reseptörleine bağlanarak oksitosin gibi kontraksiyon sayısını, uterus tonüsünde artırır ve ritmik kontraksiyonları sağlar. Bu ajanın intra müsküler olarak uygulanması, intravenöz uygulamada görüldüğü gibi tetanik kontraksiyon oluşturmasına rağmen etkisi daha uzun sürmektedir (21).

Su et al. (22) yaptığı Cochrane collarabationda yer alan ve 2635 kadını kapsayan 11 randomize kontrollü çalışma içeren meta analizde, altı çalışmada oksitosin ile karbetosin incelenmiştir; diğer 4 çalışmada syntometrine ile karbetosin, bir çalışmada da intravenöz karbetosin plasebo ile karşılaştırı Imıştır. Oksitosin ile karbetosinin karşılaştırılmasında ikisininde etkilerinin aynı olduğu saptanmıştır. Syntometrine ile karbetosinin karşılaştırılmasında tedavi etkinliği açısından fark saptanmazken, syntometrine kullanılan vakalarda bulantı ve kusma gibi yan etkilerin daha fazla olduğu görülmüştür. Plesabo ve karbetosin karşılaştırılmasında plesabo uygulanan kadınlarda kaşıntı ve kızarıklık sorunu yaşanmıştır. Sonuç olarak, postparum hemoraji tedavisinde oksitosin agonistlerinin kullanımının postpartum kanamayı önlemede ve azaltmada etkin bir tedavi olduğunu göstermektedir (I-A).

b-Ergot Alkaloidleri: Ergot alkaloid ajanları da kalsiyum-kanal mekanizmasıyla uterusun kas tabaksında uzun süreli kontraksiyonlar oluşturur. Ergot alkaloid ajanların hepsi uterusun myometriyum tabakası üzerinde aynı etkiyi oluşturmaktadır. Bu ajanlardan en etkilisi ergometrin olup, toksite açıdan ergotamin ajanından üstündür. Bundan dolayı uterotik ajan olarak ergometrin ve yarı-sentetik formu metilerergometrin diğer ergot ajanların yerini almıştır.

Syntometrin: Bu ajan $500 \mu \mathrm{g}$ ergometrinmaleat ve $5 \mathrm{IU}$ oksitosin içermektedir. Ergot prepatlarından birisi olan ergotmetrin doğada bulunmakta olup, myometriyumun, damarlardaki düz kasların kontraksiyonunu uyarmaktadır. Bu ajan kontraksiyon sayısında, süresinde artış sağlayarak uterus tonüsünü artırmakta ve bu bölgeye olan kan akımını azaltmaktadır. Şiddetli kontraksiyonlar ve ardından gevşeme evresi oluşmaktadır. Hemostazın nedeni, plasentanın bulunduğu bölgede kanama olan damarların etrafında yer alan uterus duvarının kontraksiyonlarıdır. Ergometrinin uygulaması sonucu oluşan vazokonstrüksiyon, primer olarak kapasitans damarlar üzerinde etki oluşturarak kan basıncı ve merkezi venöz basınçta artmaya neden olur. Ergometrin serotonin ve $\alpha$-adrenerjik reseptörlerinin uyarılmasını sağlayarak, endotel kaynaklı dilatasyon sağlayıcı faktörlerin salınmasını engelleyerek arterlerde vazokonstrüksiyona sebep olmaktadır (23).

Mcdonald et al. (24) yaptığı Cochrane 
collarabationda yer alan ve 9332 kadını kapsayan altı randomize kontrollü çalışmayı içeren meta analizde, oksitosin ile oksitosin+ergometrin (syntometrin) karşılaştırılmıştır. Bu çalışmada, ergometrineoxytocin, oksitosine kıyasla daha az kan kaybıyla ilişkili bulunmuştur. Ancak; ergometrine-oxytocin kullanımında, yüksek kan basıncı, bulantı ve kusma gibi yan etkilerin yaşanma durumu daha yüksek olarak belirtilmiştir. Sonuç olarak, çalışmalar syntometrin kullanımının postpartum kanamayı önlemede ve azaltmada etkin bir tedavi olduğunu göstermekte olup ancak yan etkisinin daha fazla olduğunu saptamıştır (I-C).

c-Prostaglandinler: Prostaglandin ajanları kollajenaz etkiyi, servikste elastatik, glikoaminoglikan, dermatan sülfat ve hiyalüronik asit seviyelerinde artma oluşturarak serviks açıklığını sağlar. Bu ajanlar, hücre içi kalsiyum seviyesini artırarak myometriyumda kontraksiyon oluşmasını kolaylaştııı ve ayrıca serviksin düz kasında gevşeme sağlar.

Misoprostol (cytotec) doğada bulunan prostaglandin E1 prepatının yapay analoğu olup oral olarak alındığında hızlı emilim olduğu ve biyolojik kullanılabilirlik \%80'ni bulduğu saptanmıştır. Doruk plazma seviyesine 30-60 dakika içerisinde ulaşır ve ardından hızlı olarak düşme eğilimi görülmüştür. Gebelikte misoprostol vajina mukozasından emilir. Vajina yoluyla kullanıldığında doruk seviyeye 90 dakikada ulaşılır ve sürekli azalma başlar. Misoprostol 400-1000 mg oral veya rektal yoldan uygulanabilmektedir (25).

Tunçalp et al. $(26,27)$ yaptığı Cochrane collarabationda yer alan sistematik rewiewda misoprostol ve enjekte edilebilen uterotoniklerle karşılaştırılmasında misoprostolün uterotoniklerden daha az etkili olduğu ve aynı zamanda bulantı, kusma ve ishal gibi yan etkilerin fazla olduğu saptanmıştır. Yine benzer sonuçları olan başka bir cochrane collarabationda yer alan Mousa et al. (27) yaptığı, 4052 kadını kapsayan 10 randomize kontrollü çalışmada, dört çalışmada misoprostol ile uterotoniklere ek olarak plasebo, diğer çalışmalarda subligunal misoprostol ile oksitosin karşılaştırılmıştır. Subligunal misoprostol ve uterotoniklere ek olarak plasebo uygulamasının karşılaştırılmasında uteroroniklerin tedavi için daha etkin olduğu saptanmıştır. Subligunal misoprostol ile oksitosinin karşılaştırılmasında tedavi etkinliği açısından oksitosinin daha etkin olduğu ve aynı zamanda subligunal misoprostol kullanılan vakalarda bulantı ve titreme gibi yan etkilerin daha fazla olduğu görülmüştür. Misoprostol (cytotec) kullanımı ise diğer tedaviler başarısız olduğunda ya da uygulanamadığında önerilmektedir. Yapılan randomize kontrollü çalışmalarda misoprostol kullanımının maternal mortaliteyi azaltmada önemli etkisinin olmadığı buna rağmen annede ateş ve titremenin artışı ile ilişkili olduğu belirlenmiştir (I-C).

\section{B-Uterus Kompresyonu Teknikleri}

Doğum sonrası atoni kanamasını kontrol altına almak için en önemli adım, acil olarak uterusun bimanuel kompresyonudur, kompresyon 20-30 dk veya daha fazla sürdürülmelidir. Damar yolu açılır açılmaz, sıvı replesmanının başlatılması gerekir. Grubu belirlenen ve eşleştirilen kan hazırsa verilir. Kompresyon; uterus atanosi, retansiye olmuş gebelik ürünleri, koagulopatiler ve hatta servikal laserasyona bağlı tüm kanamaları kontrol altına almakta yararlı olacaktır. Yoğun sıvı ve kan transfüzyonu idrar miktarını artıracağından, kompresyon yapılmadan önce idrar sondası takılmalıdır. Dolu mesane kompresyonu engeller ve hastayı rahatsız eder. Ayrıca bu durum tek başına uterus atonisinin ana sebebi olabilir. Uterus kompresyonu eksternal, internal ve abdominal aortaya bimanuel kompresyon olarak üç teknikle uygulanabilir (28).

Uterus kompresyonu 1997 yılından beri kullanılmaktadır. Spätling ve Schneider'in (2014) yaptığı deneysel bir çalışmada post partum hemoraji yaşayan kadınlara bandaj ile eksternal kompresyon sağlanmış ve çalışmanın sonucunda kan kaybı miktarında azalma sağlanarak yöntemin başarılı sonuç sağladığı saptanmıştır (29). Ancak bu konuyla ilgili kanıt düzeyi sağlayıp öneride bulunabilmek için iyi tasarlanmış randomize kontrollü çalışmalara gereksinim duyulmaktadır (IV-E).

\section{C-Uterus Içine Tampon Yerleştirme}

$\mathrm{PPH}$ durumunda tamponad uygulaması, uterusun bir araç aracılığı ile obstrükte edilerek kan akışının engellenmesini ifade etmektedir. Araç olarak balon kateter veya gaz sargı kullanılabilmektedir. PPH azaltma veya durdurma amacıyla tamponadın tek olarak yada destek süturları ile beraber uygulanması kullanılmaktadır. Bu yöntemde enfeksiyon ve süren kanama durumun fark edilememesi yöntemin dezavantajı olarak görülmektedir (30).

a.Sengstaken-Blakemore Tüpü: SengstakenBlakemore kateter; normalde özofagusda oluşan varis kanamaları durumunda ve kontrast madde uygulanması için kullanım sağlamaktadır. Özofagus ve mide bölümlerinden oluşan üç yollu bir kateter; $500 \mathrm{ml}$ ve üzerine dek şişirilebilmektedir. Kateter uygulanmadan önce; perforasyon komplikasyonunun 
önüne geçmek için mide balonunun ardından gelen kısmın alt bölümü kesilerek kullanılmaktadır(30). Seror et al. (31) yaptığı deneysel bir çalışmada SengstakenBlakemore kullanımı postpartum hemorajiye bağlı operasyonların \%88'ini, embolizasyonun da \%71'ini önlediği saptanmıştır. Ishii et al. (32) yaptığı 37 hastayı içeren çalışmada postpartum hemorajiyi durdurmada Sengstaken-Blakemore kullanımının \%89 oranında başarı sağladığı saptanmıştır. Bu sonuçları destekleyen yani aşırı PPH durumlarında kanamayı azaltma ve durdurmada başarılı bir yöntem olduğunu belirten raporlar bulunmaktadır (33-35). Avantajı kullanım basitliği, dezavantajı PPH'ye yönelik tasarlanmadığı için uterus kavite boşluğuna kolayca adapte olamaması durumu olarak ifade edilmiştir. Kanıt düzeyi önerebilmek için iyi tasarlanmış ve geniş örneklem grubuna sahip randomize kontrollü çalışmalara intiyaç vardır (III-C).

b.Kondom Hidrostatik Tamponad: İlk olarak Bangladeş'te görülen bu yeni yaklaşım, tamponad amaçlı steril bir kateterin uç kısmına yerleştirilen kondom ile uygulama yapılır. Katetere yerleştirilen kondom ipek ile bağlanır ve katetere izotonik verilmeye başlanır. Bir başka uygulama şekli olarak; kondomun uterus içine yerleştirilmesinin ardından 250-500 $\mathrm{ml}$ serum fizyolojik ile şişirilirerek dışarıda kalan kateter kendi üstüne katlanarıp kanama durunca iple bağlanabilir. Kanama durumu gözlemlenerek durduğu düşünüldüğünde şişirme işlemine son verilir. Balonu sabitlemek için vajen içi steril gazlı pedlerle doldurulur. Yöntemin başarı sağlayıp sağlamadığı vajinal yolla olan kanama miktarı ile belirlenir (36). Akther et al. (36) yaptıkları 23 hastayı içeren deneysel çalışmada hastaların hepsinde kanamanın 15 dakika içersinde durduğu saptanmıştır. Thapa et al. (37) yaptıkları 14 hastayı içeren çalışmada bütün vakalarda kanamayı durdurarak kondom tamponatın kanamayı önlemede etkili bir yöntem olduğunu saptamışlardır. Rathore et al. (38) yaptıkları 18 hastayı içeren çalışmada kondom tamponatının kanamayı durdurmada \%94 oranında başarılı olduğunu saptamışlardır. Örnek sayıları az olsa bile bu teknik özellikle kaynakları yetersiz sosyoekonomik düzeyi düşük ülkeler için çabuk, basit ve ekonomik bir uygulamadır. Ancak önerilebilmek için iyi tasarlanmış ve geniş örneklem grubuna sahip randomize kontrollü çalışmalara intiyaç vardır (III-C).

\section{D-Selektif Arteriyal Embolizasyon}

$\mathrm{Bu}$ işlem girişimsel radyolojide fluoroskopi rehberliğinde A.femoralis'den girerek uterus arterine embolizasyon yapılmasıdır. Bu teknik minimal invazifdir, koagulapati durumunda yapılabilir, oldukça etkindir. Embolizasyonda amaç; vajina ve uterusdan gelen aktif kanamayı durdurmak ve tekrarlamasının önüne geçmektir. Eğer bunu sağlanamazsa ardından uygulanabilecek cerrahi girişimlere de yarar sağlamak amacı ile internal iliak damarları geçici olarak tıkamak gerekmektedir. Bildirilen komplikasyonlar ateş, gluteal iskemi, hematom formasyonu, vasküler perforasyon ve enfeksiyondur (10).

Embolizasyon kısa bir süre önce uygulanmaya başlanmasına karşın faydalı, güvenli ve yüksek uygulanabilirlik nedeniyle tercih edilen bir seçenek olmuştur. Bu yöntem hastanın hayatta kalmasını sağlamanın dışında kadın iç üreme organlarına zarar gelmesini önleyerek doğurğanlığıda korumaktadır. Bundan dolayı bu yöntem önleyici tedaviye yanıt alınamayan durumlarda cerrahi işlemden önce tercih edilmesi gereken bir şeçenektir (39).

Embolizasyon işlemi başarı ile uygulandığında ek cerrahi işleme intiyaç duymadan hastanın hızla iyileşebileceği bildirilmiştir. Kanamanın durdurulmasında \%95'in üzerinde başarı şansına sahiptir, ancak zamana ve özelleşmiş araçlara ihtiyaç duyar. Vedantham et al. (39) yapmış olduğu sistematik araştırmada; bu yöntemle vajinal doğum yapan 49 kadının \%100'ünde, sezaryen doğum yapan 18 kadının \% 89'unda PPH'nin durdurulduğu bildirilmiştir. Bir başka güncel raporda belirtilen oran \% 75'dir (40). Li et al. (41) yaptığı 45 sekonder postpartum hemorajili kadına uterin arteriyel embolizasyon uygulanarak bu tekniğin kanamayı durdurmada \%100 başarı sağladığı saptanmıştır. Kim et al. (42) yaptığı 121 primer postpartum hemorajili kadına tedavi olarak uterin arteriyel embolizasyon uygulanarak tedavide \%96 oranında başarı sağladığı gösterilmiştir. Sonuç olarak, postpartum hemoraji tedavisinde bu prosedürü önermek için metolojik ve yeterli güce sahip RKÇ’ya intiyaç duyulduğu görülmektedir. Postpartum hemoraji tedavisinde arteriyel embolizasyonun kullanımını önermek için yeterli kanıt yoktur(IV-C).

\section{E-Non-Pnömatik Anti-Şok Giysi (NASG)}

Non-Pnömatik Anti-Şok Giysi (NASG) PPH'de kan kaybını en aza indirgemek ve vücudun alt bölümüne baskı yaparak hipovolemik şoku geri döndürmede acil ilk yardım tedavisinde önerilmektedir. NASG; neoprennin üç yönlü esneyebilme yeteneği ile vücudun alt bölümünde ayak bileğinden diyaframa kadar 30$40 \mathrm{~mm} \mathrm{Hg}$ çevresel karşı basınç uygulamaktadır. $\mathrm{Bu}$ basınç kanın abdomen ve bacaklarda bulunan kapasitans venlerinden beyin, akciğer ve kalp gibi hayati organlara akımını sağlar. Böylece hipovolemik şokun geri döndürülmesine yardım eder. Ortalama 
500-1.500 ml olan bu ototransfüzyon uygulama anında etki oluşturur. Kanama miktarının azalması ve kan basıncının düzelmesi panik düzeyini azaltır ve durumu bilinçli olarak değerlendirebilme imkanı sağlar. Kan transfüzyonu, cerrahi ve diğer girişimler için yapılan hazırlık sürecinde hastaların uzun süre stabil tutulabilmesine olanak sağlamaktadır. $\mathrm{Bu}$ sürede yapılacak cerrahi işlemler için veya üst merkezlere nakil için hazırlık yapılabilir. Giysi aynı zamanda imkanları kısıtlı merkezlerden yada evden, olanakları iyi merkezlere uzun sürecek olan hasta nakli sırasında kadınları hayatta tutma potansiyeli olduğu bilinmektedir(43).

Pakistan'da yapılmış 150 PPH'li kadını kapsayan iki araştırmada $(43,44)$, anti-şok giysisi uygulanan kadınların hipovolemik şok durumundayken resüsitasyona hızlı yanıt aldıkları, ayrıca tedavi sürecini beklerken uzun süre stabil kaldıkları belirtilmiştir. Araştırmada giysinin 30 saatten fazla kalmasına rağmen herhangi bir yan etki oluşturmadığı, stabil kalabilme süresini uzattığı ve kan transfüzyonu için ortalama beş buçuk saat zaman sağladığı bildirilmiştir (45).

Mısır ve Nijerya'da yapılan; dış gebelik, abortus, uterus rüptürü, atonisi ve PPH'si olan 804 kadın ile yapılmış NASG araştırmasında; anti-şok giysi kullanılan grubun kanama oranında \%46'lık azalma olduğu görülmüştür. Aynı çalışmada ağır şok durumunda olan, uygun olmayan ortamlarda, tecrübesiz kişiler tarafından yaptırılan doğumlar ve ardından gelişen kanamaların tedavi edilmediği durumlarda kadınların stabile olmasını sağlamak için kullanımın başarı sağlayacağı bildirilmektedir. Anti-şok giysi uygulaması; PPH'de kaybedilen kan miktarında azalma, şok durumunda resüsitasyon uygulanmasına olanak sağlaması dışında anne mortalite oranında ve ileri komplikasyonlarda azalma sağladığını gösteren daha büyük örneklemde güçlü deneysel araştırmalara intiyaç duyulmaktadır. Çoklu yarı deneysel araştırmalar ve klinik araştırmalarla güçlü kanıtlar sağlanırsa PPH ve hipovolemik şok durumlarından kaynaklanan anne mortalite ve morbidite oranında azalma sağlama potansiyeli yüksektir. Ancak NASG tedavi edici özelliğe sahip olmayıp sadece tedavi sürecinde zaman kazandırmaktadır (46). PPH ve hipovolemik şokta antişok giysisinin kullanılmasına yönelik tanımlayıcı olgu serileri ile sağlanmış güçlü kanıtın bulunmamasına rağmen kullanımı önerilmektedir (III-C).

\section{3-CERRAHI}

\section{A-Uterus Kompresyon Sütürleri}

B-Lynch Sütürü laparatomi sırasında konulan kompresyon sütürüdür. Sütürün kanamayı kontrol edip etmeyeceğini anlamak için önce bimanuel kompresyon yapılmalıdır. Bu faydalı olursa sütür konur. En basit şekliyle, kompresyon sütürleri uterusun alt segmentinde serviksin $1 \mathrm{~cm}$ üstünden ve uterin arterin $2 \mathrm{~cm}$ medialinden başlanarak önden arkaya doğru konulan yine karşı tarafta uterusun aynı hizasından çıkılan emilebiir sütürlerdir. Bu sütürler daha sonra uterusun üst kısmında bağlanırlar ve uterusa kompresyon yaparlar. Plesanta previa yada akreataya bağlı alt uterin segment kanamalarında myometriyal yatağa derin şekilde konulan sütürlerle kanama durdurulabilir (10).

Kaoiean'ın (2013) yaptığı 24 postpartum hemorajili kadını içeren çalışmada B-Lunch sütür uygulanarak vakaların \%95.8'inde başarılı olunduğunu saptamış. Bu çalışmada B-Lynch sütür postpartum hemorajinin tedavisinde etkili ve güvenli bir cerrahi seçenek olduğunu gösterilmiştir (47). Aboulfalah et al. (48) yaptıkları 15 hastayı içeren deneysel çalışmada bir hastada histerektomiye ihtiyaç duyulmuş, diğer 14 hastada sütür ile kanamanın durduğu saptanmıştır. Histerektomiye başvurulmadan önce yapılması gereken bir girişim olarak savunulmuştur. Eldeki veriler, postpartum hemoraji tedavisinde uterus kompresyon sütürleri uygulaması hakkında güvenli karar vermeyi sağlamak için yeterli olmadığını göstermektedir (IV-C).

B-Arteriyel Ligasyon

\section{a.Hipogastrik yada Internal İliak Arterlerin Bağlanması}

Uterusa kan götüren ana damar hipogastrik arterlerdir, bu arterlerin tek veya her ikisininde bağlanması pelvise olan kan akımını bozacaktır. Eski zamanlarda hipogastrik arterleri bağlamanın o bölgeye olan bütün kan akışını engellediği düşünülmekteydi. Ancak bu bilginin yanlış olduğu zaman içinde anlaşılmaya başlamıştır. Çalışmalar bu yöntemin PPH'de pelvis sirkülasyonunun yalnızca \% 48'inde azalma sağlandığını bildirmiştir. Bu arterin bağlanacağı bölgenin ilerisinde bulunan büyük anastomoz ağı arterlerin bağlanmasının ardından hemen fonksiyon göstererek bölgenin kansız kalmasını engeller. Bu işlemden sonra arteriyal nabızda azalma görülür. Nabız yokluğu ve basıncın azalması durumu damarlarda oluşacak trombozun kalıcı olacağını düşündürür. Bildirilen komplikasyonlar; kanama, yanlışlıkla ana iliyak arterin bağlanması, sinir yaralanması ve ameliyat süresinde artmadır. 
Ayrıca doğru uygulamanın durumda komplikasyon oranlarında artma ve başarı oranlarında (\%25-60) azalma saptanmıştır (49).

Chelli et al. (50) yaptıkları 57 kadını içeren retrospektif çalışmada olgulara bilateral hipogastrik arterler ligasyonu uygulanarak, 57 hastanın 47'sinde (\%82.45) tedavide başarılı olunduğu bildirilmiştir. Boynukalın et al. (51) yaptıkları 26 hastayı içeren retrospektif bir çalışmada bilateral hipogastrik arterlerin bağlanması ile 26 hastanın 20'sinde (\%76.9) kanamanın durdurulduğu bildirilmiştir. Sonuç olarak; postpartum hemoraji tedavisinde bilateral hipagastrik arter ligasyon kullanımını önermek için kanıt ve uzun vadeli sonuçları hakkında bilgiler nispeten eksik olduğundan, metolojik ve yeterli güce sahip daha fazla RKÇ intiyaç duyulduğu belirtilmektedir (IV-D).

\section{b.Uterin ve/veya Ovarian Arterlerin Birlikte Bağlanması}

Sezeryan ameliyatı sırasında bu teknik ilk seçenek tedavidir. Üreterlerin tanımlanmasından sonra servikse mümkün olduğunca yakın yerden alt uterin segmentin lateralinden broad ligamente doğru uterin damarların lateraline sütür konur (10). Waters (52) bilateral internal iliak arter ligasyonuna alternatif bilateral uterin arter ligasyonunu önermiştir. $\mathrm{Bu}$ yönteminde başarı şansı başka bir çalışmada \%80-96 arasında olduğu bildirilmiştir (53). Abd Rabba (54) sadece uterin arterin bağlanmasının kanamayı durdurmadığıvakalarda ovarian damarları da bağlamış \%100 başarı elde etmiştir. Hebish ve Hunch'un (55) yaptığı 13 vakayı içeren çalışmada uterin arterlerin bağlanması ile 12 kadında (\%92) kanamanın başarılı bir şekilde durduğu saptanmıştır. Gezginç et al. (56) yaptığı sekiz hastayı içeren çalışmada hastalara tedavi için uterin ve ovarian arterlerin birlikte bağlanmasının yanı sıra B-Lynch sütür tekniğide uygulanmıştır. Çalışma sonucunda yedi kadında kanamanın durduğu saptanmıştır. Ancak uterin ve/ veya ovarian arterlerin birlikte bağlanmasının etkinliği ile ilgili sunulan kanıtlar yetersizdir. Bu nedenle uterin ve/veya ovarian arterlerin birlikte bağlanmasının postpartum hemoraji üzerine etkilerini belirleyecek iyi tasarlanmış randomize kontrollü çalışmalara ihtiyaç vardır (IV-C).

\section{C-Total abdominal Histerektomi}

Histerektomi, sağaltıcıdır ve genellikle doğum sonrası kanamayı kontrol eden en kesin yöntemdir. Çok sayıda doğum yapan veya genel durumu daha geniş bir cerrahi müdahale için müsait olmayan kadınlarda, uterusla ilgili başka bir patoloji yoksa, tüp ligasyonu ile birlikte veya tek başına, uterus rüptürünün hemostatik onarımı tercih edilir. Peripartum histerektomi uygulaması iyice tanımlanmalı ve tekniğin de gebe olmayan kadınlardan farklılıkları vardır. Dokular daha damarlı ve gebelikte meydana gelen anatomik değişiklikler nedeniyle üriner alan yaralanmaları daha sık meydana gelmektedir. Ooferektomiye neden olabilecek ovaryen ligamentin dikkatsiz klemplenmesinden kaçınmaya dikkat etmek önemlidir(57). NGC Gudline Summary 2009 göre özellikle plesanta akreata ve uterus rüptürü durumlarında histerektomiye başvurulmasını önermektedir(58)(V-D).

Tablo1: PPH Yönetiminde Kanıta Dayalı Yaklaşımlar

\section{SONUÇ}

Klinik uygulamada bakımın kalitesini sağlamak, sonuçları iyileştirmek, sonuçlarda farklılık oluşturmak, bakımın standardize olmasını sağlamak ve sağlık profesyonellerinin memnuniyet düzeyinde artma sağlamak sadece kanıt temelli yaklaşımlarla mümkündür. Dünyada olduğu gibi ülkemizde de KDU, henüz tartışıldığı, konuşulduğu kadar uygulama alanına yansımamıştır ve bu alanda birçok problem yaşanmaktadır (89). 20. yy. ile birlikte sağlık alanındaki, hastaların tedavi ve bakımına yönelik olan gelişmeler vede toplumda iyi bir sağlık hizmeti almaya yönelik oluşan beklenti sonucu; sağlık hizmeti sağlayıcılarının eğitim, uygulama ve yönetim açısından kendilerini geliştirmeleri gerekliliğini vurgulamaktadır (59).

Çalışma sonuçları ve kanıta temelli kılavuzlar temel alındığında, postpartum hemorajinin önlenmesinde ve tedavisinde uterotonik ilaçlar (oksitosin, karbetosin, ergot alkoloidleri, syntometrin, misoprostol) dışındaki çalışmaların kanıt düzeylerinin yeterli olmadığını göstermektedir. Yapılan çalışmalarda özellikle cerrahi girişimlere dayalı çalışmalarda metodolojik eksikliklerin olduğu görülmektedir. Buna ek olarak yapılan çoğu araştırmada, hipotezi test edecek örneklem büyüklüğünün de sınırlı olduğu görülmektedir. Bu nedenle postpartum hemorajinin önlenmesinde ve tedavisinde olumlu sonuçlar elde edilmesine karşın çalışma sonuçlarını genelleyebilmek ve karşılaştırma yapabilmek mümkün değildir. İyi planlanmış, yeterli sayıda denek üzerinde yapılan güçlü randomize çalışmalara gerek vardır. Sonuç olarak; postpartum hemorajiyi önlemeye ve tedaviye yönelik girişimlerin kanıtlarla temellendirilmesi için daha fazla randominize çalışmaların yapılmasına intiyaç duyulduğu görülmektedir. 
Table 1. PPH Yönetiminde Kanıta Dayalı Yaklaşımlar

DOĞUMUN ÜÇÜNCÜ EVRESININN YÖNETIMI

Cochrane-Pubmed-

Google scholardan

\section{Taranan Makale}

AKTIF YÖNETIM

Rogers et al.1998

Prendiville et al. 2000

KORDON KLEMPLEME

Begley et al. 2011

Rabe et al. 2004

McDonald ve Abbott 2008

Mcdonald ve Middleton 2008

Araştırma Sonuçları

Öneri Düzeyi

PPH, postpartum anemi

kan transfüzyonu ihtiyacını,

insidansını ve şiddetininde azalma

I-A

Geç klempleme ile PPH insidansında

fark gösterilememiş; ancak fototerapi gerektiren neonatal sarılık ve yenidoğanlarda 6 . aya kadar yüksek hemoglobin ve ferritin düzeylerinin saptanma insidansında belirgin artış

KORD ÇEKME

UTERUS MASAJI
Prick et al.2013

Sheldon et al. 2013

Du ve ark 2014

Hofmeyr et al.2013

İldan ve Kavlak 2014

Sangkomkamhang 2008
PPH önlediği, kan tranfüzyonu

ve uterotonik kullanımında azalma

I-A

Kan kaybında, ilave uterotoniklerin kullanımında, kan transfüzyonuna duyulan intiyaç oranında azalma
II-B

TEDAVi

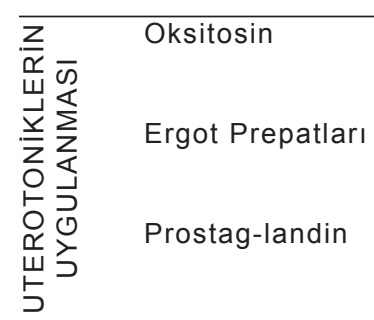

UTERUS KOMPR.

TAMPONAD

EMBOLIZASYON

NASG
Cotter et al. 2007

Westhoff et al. 2013

Su et al. 2012

McDonald et al. 2009

Westhoff et al. 2013

Tunçalp ve ark 2012

Mousa ve ark 2014

Spätling ve Schneider 2014

Seror et al.2005

Ishii ve ark 2012

Rathore et al.2012

Frenzel ve ark 2005

Condous et al. 2003

Japaraj\& Raman 2003

Akther et al. 2003

Thapa et al.2010

Vedantham et al. 1997

Lix et al. 2012

Ojala et al. 2005

Kim et al.2013

Brees et al. 2004

Hensleigh 2002

Miller et al.2004

Turan veark 2011
Kan kaybında azalma ve saptanan

bir yan etkinin olmaması

I-A

Kanama kontrolünde oksitosinden daha etkin, Mide bulantısı, kusma ve yüksek kan basıncı gibi yan etkilerde artma Kanama kontrolünde oksitosinin daha etkin, Bulantı, kusma, ishal ve titreme gibi yan etkilerde artma

Kan kaybı miktarında azalma,

PPH yönetiminde başarısında artma IV-E

Uterin atoniye bağlı aktif PPH'yı geçici olarak kontrol etmek için ucuz, basit ve çabuk bir girişim

I-C

I-C

III-C

PPH önlemede başarı oranı \% 96.3, teknik yetersizliğe bağlı yan etkiler

IV-C

\%46 oranında kan kaybında azalma, nihai tedaviyi beklerken uzun

stabilizasyon dönemi

III-C

CERRAHI

B-LYNCH SÜTÜRLARI
ARTERLERIN BAĞLANMASI

HISTEREKTOMI
Kaoiean 2013

Aboulfalah et al. 2014

Chelli et al. 2010

Boynukalın et al. 2013

Waters 1952

Abd Rabba 1994

Hebish ve Hunch 2002

Gezginç et al. 2012

Gowri Ramanathan \&

Arulkumaran 2006

Guedline Summary

(NGC-8394) 2009
Myometriuma eksternal bası

uygulanmasıyla kanama kontrolünü sağladığı IV-C

PPH'yı önlemede, ayrıca atoni ve genital

kanal travmasına bağlı PPH'yi tedavi

etmede yararlı olduğu

IV-C

Üriner alan yaralanmaları ve ooferektomi oranında artma,özellikle plesanta akreata ve uterus rüptürü durumlarında $\mathrm{pph}$ önlemede en etkin seçenek 
Çıkar Çatışması: Çalışmada herhangi bir çıkar çatışması yoktur.

Finansal Çıkar Çatışması: Çalışmada herhangi bir finansal çıkar çatışması yoktur.

Yazışma Adresi: Gül Ertem, Ege Üniversitesi Hemşirelik Fakültesi Kadın Sağlığı ve Hastalıkları Hemşireliği Anabilim Dalı, Posta kodu; 35040, Bornova, IZMIR

Tel: 02323881103- 5573 Faks: 0232-3886374

e-posta: ertemgul@gmail.com

\section{KAYNAKLAR}

1. Öztopcu C. Obstetrik El Kitabı. Ankara Medikal\&Nobel Tıp Kitap Sarayı, Ankara, 2008;482-4.

2. Sevil Ü, Ertem G. Perinatoloji ve Bakım. İzmir:Ankara Nobel Tıp Kitapevi. 2016:409-29.

3. Rogers J, Wood J, McCandlish R, et al. Active versus expectant management of third stage of labour: The Hinchingbrooke randomized controlled trial. Lancet 1998;351: 693-9.

4. Prendiville WJ, Elbourne D, McDonald S. Active versus expectant management in the third stage of labour. Cochrane Database Syst Rev 2000;3:2-5.

5. Begley CM, Gyte GML, Devane D, et al. Active versus expectant management for women in the third stage of labour (Cochrane Review). The Cochrane Library 2011;11:2-27.

6. The World Health Organization. The World Health Report 2005 - Make Every Mother and Child Count. http://www.who. int/whr/2005/en/ E.T:10.12.2014.

7. Rabe H, Reynolds G, Diaz-Rossello J. Early versus delayed umbilical cord clamping in preterm infants. Cochrane Database of System 7 atic Reviews 2004;4:2-7.

8. McDonald SJ, Abbott JM. Effect of timing of umbilical cord clamping of term infants on maternal and neonatal outcomes (Review). Cochrane Database of Systematic Reviews 2008;2:3-10.

9. McDonald SJ, Middleton P. Effect of timing of umblical cord clamping of term infants on maternal and neonatal outcomes. Cochrane Database Syst Rev 2008(2):CD004074.

10. Has R, Kara AÇ. Postpartum kanamalar. Çiçek $M N$, Mungan MT, eds. Klinikte Obstetrik ve Jinekoloji, Güneş Tıp Kitapevleri, Ankara, 2007;397-401.

11. Prick BW, Vos AA, Hop WCJ, et al. The current state of active third stage management to prevent postpartum hemorrhage: a cross-sectional study. Nordic Federation of Societies of Obstetrics and Gynecology, Acta Obstetricia et Gynecologica Scandinavica 2013;92:1277-83.

12. Sheldon WR, Durocher J, Winikoff B, et al. How effective are the components of active management of the third stage of labor? BMC Pregnancy and Childbirth 2013;13(46):2-8.

13. Du Y, Ye M, Zheng F. Active management of the third stage of labor with and without controlled cord traction: A systematic review and meta-analysis of randomized controlled trials. Acta Obstetricia et Gynecologica Scandinavica 2014;93:62633.

14. Sangkomkamhang US. The effectiveness of evidence based practice for reducing early postpartum hemorrhage. Khon Kaen Hospital Medical Journal 2008;32 (2):239-48.

15. Hofmeyr GJ, Abdel-Aleem H, Abdel-Aleem MA. Uterine massage for preventing postpartum haemorrhage(Cochrane Review). The Cochrane Library 2012;7:3-8.

16. Illdan Çalım S, Kavlak $O$. The effect of uterıne massage during early postpartum period on uterus involution and amount of lochia rubra. Gümüşhane Üniversitesi Sağlık Bilimleri Dergisi / Gümüşhane University Journal of Health Sciences 2014;3(4):1005-16.

17. Sanborn BM, Dodge K, Monga $M$, et al. Molecular mechanisms regulating the effects of oxytocin on myometrial intercellular calcium. Adv Exp Med Biol 1998; 449:277-86.

18. Parker SL, Schimmer BP. Pituitary hormones and their hypothalamic releasing hormones. In: Goodman and Gilman, eds. The pharmacological basis of therapeutics.11th ed. New York: McGraw Hill, 2006:1489-510.

19. Cotter A, Ness A, Tolosa J. Prophylactic use of oxytocin in the third stage of labour, Cochrane Database Syst Rev 2007;4:16.

20. Westhoff G, Cotter MA, Tolosa EJ. Prophylactic oxytocin for the third stage of labour to prevent postpartum haemorrhage (Cochrane Review). The Cochrane Library 2013;10:2-12.

21. Hunter DJ, Schulz P, Wassenaar W. Effects of carbetocin, a long acting oxytocin analog on the postpartum uterus. Clin Pharm Therapeu 1992;52:60-7.

22. Su L, Chong Y, Samuel M. Carbetocin for preventing postpartum haemorrhage (Cochrane Review). The Cochrane Library 2012;4:1-13.

23. Rall TW. Oxytocin, prostaglandins, ergot alkaloids, and other drugs; tocolytic agents. In: Goodman A, Gilman A, Rall TW, Nies AS, Taylor P, eds. Goodman and Gilman's the pharamacological basis of therapeutics. Toronto: Pergamon Press, 1990:933-53.

24. McDonald SJ, Abbott JM, Higgins SP. Prophylactic ergometrine-oxytocin versus oxytocin for the third stage of labour(Cochrane Review). The Cochrane Library 2009;1:2-8.

25. More B. Misoprostol: An old drug, new indications. J Postgrad Med 2002;48:336-9.

26. Tunçalp Ö, Hofmeyr GJ, Gülmezoglu AM. Prostaglandins for preventing postpartum haemorrhage (Cochrane Review). The Cochrane Library 2012;8:2-15.

27. Mousa HA, Blum J, Abou El Senoun G, et al. Treatment for primary postpartum haemorrhage (Cochrane Review). The Cochrane Library 2014;2:2-17.

28. TC Sağlık Bakanlığı, Ana Çocuk Sağlığı ve Aile Planlaması Genel Müdürlüğü: Doğum sonu kanama yönetimi, acil obstetrik bakım klinisyen eğitimi-katılımcı rehberi. Buluş tasarım ve matbaacılık hizmetleri, Ankara, 2007;89-107.

29. Spätling L, Schneider H. "Sumo-compression" Stops Post PartumHaemorrhage. Z Geburtshilfe Neonatol 2014;218(5):223-5.

30. Ferrazzani S, Guariglia L, Caruso A. Therapy and prevention of obstetric haemorrhage by tamponade using a balloon catheter. Minerva Ginecol 2004;56:481-4.

31. Seror J, Allouche C, Elhaik S. Use of Sengstaken-Blakemore tube in massive postpar-tum hemorrhage: A series of 17 cases. Acta Obstet Gynecol Scand 2005;84:660-4.

32. Ishii T, Sawada K, Koyama S, et al. Balloon tamponade during cesarean section is useful for severe post-partum hemorrhage due to placenta previa. J Obstet Gynaecol Res 2012;38(1):102-7.

33. Frenzel D, Condous GS, Papageorghiou AT, et al. The use of the 'tamponade test' to stop massive obstetric haemorrhage in placenta accreta. Br J Obstet Gynaecol 2005;112: 676-7.

34. Condous GS, Arulkumaran S, Symonds I, et al. The 'Tamponade test' in the management of massive postpartum hemorrhage. Obstet Gynecol 2003;101:767-72. 
35. Japaraj RP, Raman S. Sengstaken-Blakemore tube to control massive postpartum haemorrhage. Med J Malaysia 2003;58:604-7.

36. Akhter S, Begum MR, Kabir Z,et al. Use of a condom to control massive postpartum hemorrhage. Med Gen Med 2003;115:38.

37. Thapa K, Malla B, Pandey S, et al. Intrauterine condom tamponade in management of post partum haemorrhage. $\mathrm{J}$ Nepal Health Res Counc. 2010;8(1):19-22.

38. Rathore AM, Gupta S, Manaktala U, et al. Uterine tamponade using condom catheter balloon in the management of nontraumatic postpartum hemorrhage. J Obstet Gynaecol Res. 2012;38(9):1162-7.

39. Vedantham S, Goodwin SC, McLucas B, et al. Uterine artery embolization: An underused method of controlling pelvic hemorrhage. Am J Obstet Gynecol 1997;176:938-48.

40. Ojala K, Perala J, Kariniemi J, et al. Arterial embolization and prophylactic catheterization for the treatment for severe obstetric hemorrhage. Acta Obstet Gynecol Scand 2005;84:1075-80.

41. Li X, Wang Z, Chen J, et al. Uterine artery embolization for the management of secondary postpartum haemorrhage associated with placenta accreta. Clin Radiol 2012;67(12):716.

42. Kim TH, Lee HH, Kim JM, et al. Uterine artery embolization for primary postpartum hemorrhage. Iran J Reprod Med 2013;11(6):511-8.

43. Hensleigh PA. Anti-shock garment provides resuscitation and haemostasis for obstetric haemorrhage. $\mathrm{Br} \mathrm{J}$ Obstet Gynaecol 2002;109: 1377-84.

44. Brees C, Hensleigh PA, Miller S, et al. A non-inflatable antishock garment for obstetric hemorrhage. Int J Gynaecol Obstet 2004;87:119-24.

45. Miller S, Lester F, Hensleigh P. Prevention and treatment of postpartum hemorrhage: New advances for low-resource settings. J Midwifery Womens Health 2004;49:283-92.

46. Turan J, Ojengbede O, Fathalla M, et al. Positive effects of the non-pneumatic anti-shock garment on delays in accessing care for postpartum and postabortion hemorrhage in Egypt and Nigeria. J Women's Health 2011;20(1):91-7.

47. Kaoiean S. Successful use of the B-Lynch uterine compression suture in treating intractable postpartum hemorrhage after cesarean delivery in Rajavithi Hospital. J Med Assoc Thai 2013;96(11):1408-15.

48. Aboulfalah A, Fakhir B, Ben Kaddour YA, et al. A new removable uterine compression by a brace suture in the management of severe postpartum hemorrhage. Front Surg 2014;1(43):1-3.

49. Kelly $\mathrm{H}$. Ligation of both internal iliac arteries for hemorrhage in hysterectomy for carci $n$ noma uteri. Bull John Hopkins Hosp 1894;5:53.

50. Chelli D, Boudaya F, Dimassi K, et al. Hypogastric artery ligation for post-partum hemorrhage. J Gynecol Obstet Biol Reprod (Paris) 2010;39(1):43-9.

51. Boynukalin FK, Boyar H, Gormus H, et al. Bilateral hypogastric artery ligation in emergency setting for intractable postpartum hemorrhage: a secondary care center experience. Clin Exp Obstet Gynecol 2013;40(1):85-8.

52. Waters E. Surgical management of postpartum hemorrhage with particular reference to ligation of uterine arteries. Am J Obstet Gynecol 1952:64:1143-8.

53. O'leary JA. Uterine artery ligation for control of postpartum hemorrhage. Obstet Gynecol 1974:43:849-53.

54. Abd Rabbo SA. Stepwise uterine devaskularizasyon: Anovel technique for management of uncontrollable postpartum hemorrhage with preservation of the uterus. Am J Obstet Gynecol 1994:171:694-700.

55. Hebisch G, Huch A. Vaginal uterine artery ligation avoids high blood loss and puerperal hysterectomy in postpartum hemorrhage. Obstet Gynecol 2002;100(3):574-8.

56. Gezginç K, Yazici F, Koyuncu T, et al. Bilateral uterine and ovarian artery ligation in addition to B-lynch suture may be an alternative to hysterectomy foruterine atonic hemorrhage. Clin Exp Obstet Gynecol 2012;39(2):168-70.

57. GGowri Ramanathan G, Arulkumaran S. Postpartum hemorrhage. Current Obstetrics Gynecology 2006;16:6-13.

58. Guedline Summary NGC-8394. Prevention and management of postpartum haemorrhage. London (UK): Royal College of Obstetricians and Gynaecologists (RCOG). 2009;24 p. (Green-top guideline; no. 52).

59. Kocaman G. Hemşirelikte kanıta dayalı uygulama. Hemşirelikte Araştırma Geliştirme Dergisi 2003;2:61-69. 